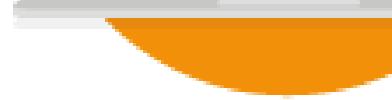

\title{
HETEROGENEIDADE DE POLÍTICAS PÚBLICAS DE FORMAÇÃO DOCENTE
}

\author{
Rosangela Vargas Cassola - FATEC SENAI CG/Brasil \\ E-mail: rcassola@brturbo.com.br
}

\section{RESUMO:}

Objetivamos identificar a potencialidade de utilização da TV Escola na formação contínua de professores que trabalham com alunos que apresentam necessidades especiais. A coleta de dados ocorreu em fases: usamos como instrumento um questionário, realizamos entrevista e procedemos a utilização da Técnica de Grupo Focal em seis encontros presenciais. Os dados revelam que os professores desconhecem os Programas da Série Educação Especial da TV Escola, bem como o conceito de deficiência mental e indicam que é possível usar a TV Escola como meio de formação contínua desde que considerados três aspectos: 1) aspectos organizacionais da escola; 2) questões profissionais de formação docente e 3) políticas de implantação da TV Escola.

Palavras-chave: FORMAÇÃO; PROFESSORES; TV ESCOLA.

\section{INTRODUÇÃO}

A educação a distância a depender do objetivo político, da ciência e dos recursos metodológicos que lhe dê forma, possibilita, como outros modos de ensino, a aquisição de conhecimentos, o desenvolvimento de habilidades e a formação de hábitos. Para Luckesi (2001) a educação a distância possibilita a democratização do ensino e a linearidade da cultura, possibilitando a culturas locais a reelaboração de conteúdo.

Nesse sentido, o Ministério de Educação e Cultura produziu os programas da TV Escola que sob a forma de um programa de educação a distância, tem o objetivo de capacitar os professores. Segundo Lima (2000), o governo federal tem investido verbas significativas na implantação/manutenção/efetivação deste programa e avaliações são necessárias para verificar a potencialidade desse como meio de proporcionar ao professor uma melhoria de sua prática. 


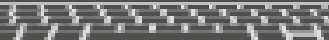
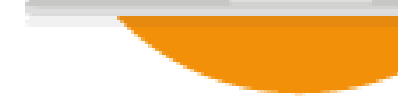

Inúmeros pesquisadores preocuparam-se em analisar as apropriações dos profissionais da educação que trabalham nas séries iniciais do ensino fundamental nas escolas públicas quanto aos programas da TV Escola.

Castro (1998) em sua pesquisa constatou que o Programa da TV Escola - Salto para o Futuro possibilita reflexões aos professores, mas que estas reflexões pouco modificam a prática pedagógica destes professores constatou ainda que o programa não substitui as capacitações presenciais oferecidas pelas Secretarias de Educação.

Semelhante às constatações de Castro (1998), Marques (1998), em sua dissertação registrou que a comunidade escolar ainda não aceita as novas tecnologias como formas de aprendizagem e que tanto os Programas da TV Escola quanto os programas de informática não alteraram as atitudes pedagógicas dos docentes.

Lins (1998) procurou verificar os limites e possibilidades do Programa TV Escola e para isso contextualizou as políticas públicas, priorizando a formação de professores. Hidalgo (1999) e Lima (2000) no decorrer de sua pesquisa compreenderam ser fundamental a presença de um supervisor/coordenador/organizador dos Programas da TV Escola para que os professores se apropriem dos Programas exibidos e que isto seja revertido em mudanças de atitudes na prática pedagógica.

Scapin (2003), em sua pesquisa também verificou a importância do coordenador/supervisor para a apropriação dos Programas da TV Escola.

De acordo com as pesquisas citadas poucos são os professores que utilizam os Programas exibidos pela TV Escola para a sua própria formação contínua. A maioria dos professores utiliza os Programas exibidos pela TV Escola em sala de aula com os alunos e principalmente inexistem pesquisas nesta área acerca da educação especial, desencadeando uma indagação: há uso dos Programas produzidos pela TV Escola da Série Educação Especial, destinados especificamente para os professores que trabalham com alunos com necessidades especiais?

A intenção da SEED, ao exibir os Programas da TV Escola que contemplam a Educação Especial, é subsidiar a prática e a formação dos docentes. 


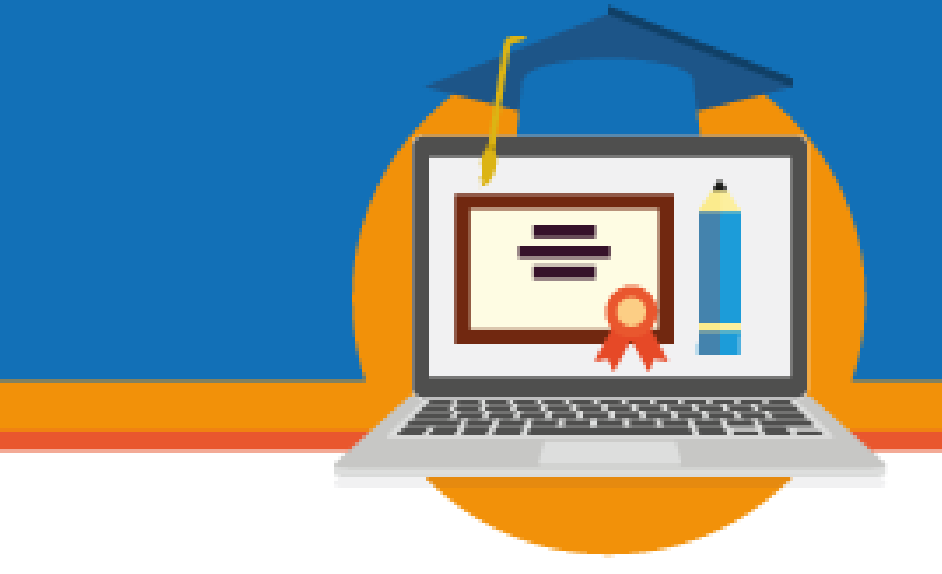

Diante dessa realidade, objetivamos identificar a potencialidade de utilização da TV Escola na formação contínua de professores que trabalham com alunos que apresentam necessidades educacionais especiais.

\section{A PESQUISA: CAMINHOS PERCORRIDOS}

Para alcançarmos nosso intento de identificar a potencialidade de utilização da TV Escola na formação contínua de professores que trabalham com alunos que apresentam necessidades especiais, optamos por desenvolver uma pesquisa qualitativa. A pesquisa qualitativa nos possibilita compreender melhor a realidade, de acordo com Triviños (1997, p. 137) “a pesquisa qualitativa não admite visões isoladas, parceladas, estanques, ela se desenvolve em interação dinâmica retroalimentada, reformulando-se constantemente". A pesquisa qualitativa tem sido bastante utilizada em pesquisas na área da educação, em função de sua abrangência junto aos fenômenos humanos e sociais.

Para alcançarmos nosso objeto de pesquisa foi necessária a formulação de uma pesquisa com duas partes, sendo que o único critério para participar das duas partes da pesquisa era o de ser professor das séries iniciais do ensino fundamental em escola pública.

\subsection{CAMINHOS PERCORRIDOS: PARTE 1}

Na primeira parte da pesquisa, buscamos explorar e compreender as concepções dos professores que trabalham com alunos com necessidades especiais sobre o uso da TV Escola para formação contínua dos professores das quatro primeiras séries do ensino fundamental de um município da região centro-oeste do estado de Mato Grosso do Sul. Para isso utilizamos como instrumento para a coleta de dados um questionário com trinta e quatro questões. Pautamo-nos na técnica de análise de conteúdo junto às questões abertas e as questões fechadas foram tabuladas com o Programa SSPS Windows - versão 10. 


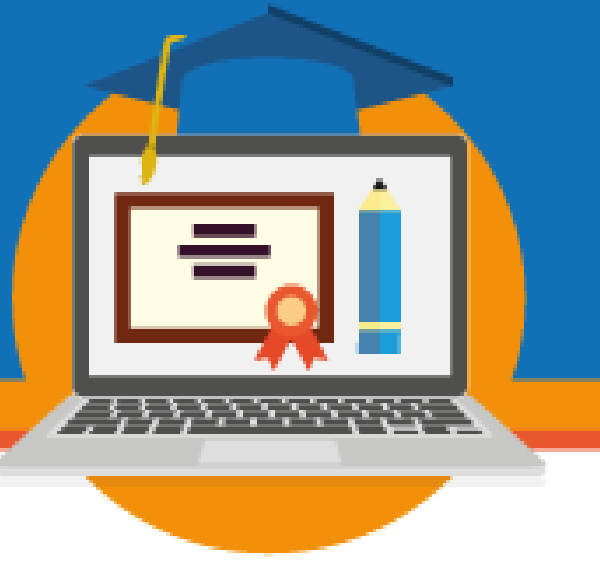

Entre as questões gradualmente organizadas do questionário, podemos evidenciar: a definição de formação contínua, os momentos de formação contínua que os professores consideram efetivo para alterações positivas na prática pedagógica, os momentos que possibilitam formação contínua na proposta pedagógica da escola e a necessidade de espaços para estudo dentro da própria escola.

\subsection{CAMINHOS PERCORRIDOS: PARTE 2}

Na segunda parte da pesquisa buscamos, a partir dos resultados da primeira parte da investigação, analisar a potencialidade de utilização da TV Escola por parte dos professores das quatro primeiras séries do ensino fundamental que trabalham com alunos com necessidades educacionais especiais. Para isso procedemos a uma entrevista com nove questões e ainda realizamos seis encontros com o Grupo Focal.

No primeiro momento da $2^{\mathrm{a}}$ parte da pesquisa realizamos uma entrevista junto aos professores informantes da pesquisa. De acordo Minayo (1999, p. 107), a entrevista é um instrumento privilegiado de coleta de informações para as ciências sociais, em função da "(...) fala ser reveladora de condições estruturais, de sistema de valores, normas e símbolos e ao mesmo tempo ter a magia de transmitir, através de um porta-voz, as representações de grupos determinados".

Desta forma, através da entrevista objetivamos verificar se os professores dos alunos que apresentam necessidades educacionais especiais compreendem o conceito de deficiência mental, já que esta é a deficiência com maior índice nas escolas públicas brasileiras e ainda se consideram que podem aprender através do uso do videocassete em situação de formação contínua.

Para obtermos estas respostas, seguimos um roteiro previamente estruturado. Para Minayo (1999, p. 99), um roteiro de entrevista "serve para apreender o ponto de vista dos atores sociais previstos nos objetivos da pesquisa, para orientar uma conversa com finalidade, que é a 
entrevista (...)". Após a realização das entrevistas, partimos para um segundo momento na segunda parte da pesquisa.

No segundo momento da $2^{\mathrm{a}}$ parte da pesquisa realizamos os encontros com o Grupo Focal.

Segundo Morgan (1997 apud Gondim 2002) o grupo focal pode ser definido como uma técnica de pesquisa qualitativa, que coleta informações por meio das interações grupais ao se discutir um tópico específico sugerido por um pesquisador, coordenador ou moderador do grupo. Ocupa uma posição intermediária entre a observação participante e as entrevistas em profundidade (...).

O Grupo Focal é um instrumento de coleta de dados que serve para observar os processos de interação humana que contribuem para a formação contínua, bem como, para analisar o compartilhamento de opiniões em relação ao tema estudado.

Ao fazer uso da técnica de Grupo Focal objetivamos levar os professores a tomar conhecimento da TV Escola e assim poder avaliar se os programas da Série Educação Especial são pertinentes à própria formação dos mesmos e ao contexto de sala de aula no atendimento aos alunos que apresentam necessidades educacionais especiais.

Ao serem convidados, conforme Quadro 1, somente um dos professores da escola estadual e quatro professores das escolas municipais aceitaram participar dos encontros com o grupo focal.

Quadro 1 - Participantes do Grupo Focal

\begin{tabular}{|c|c|c|c|}
\hline ESCOLAS & $\begin{array}{lr}N^{o} \text { de professores } \\
\text { informantes } & \text { que } \\
\text { participaram da } 1^{\text {a }} & \text { parte } \\
\text { da pesquisa } & - \\
\text { respondendo } & \text { ao } \\
\text { questionário }\end{array}$ & $\begin{array}{l}\mathrm{N}^{\mathrm{o}} \text { de professores } \\
\text { informantes que } \\
\text { participaram da } 2^{\mathrm{a}} \text { parte } \\
\text { da pesquisa - } \\
\text { respondendo a entrevista }\end{array}$ & $\begin{array}{l}\mathrm{N}^{\mathrm{o}} \text { de professores } \\
\text { informantes que } \\
\text { participaram da } 2^{\mathrm{a}} \text { parte } \\
\text { da pesquisa - encontro } \\
\text { com o Grupo Focal }\end{array}$ \\
\hline $\begin{array}{l}\text { Escola } \\
\text { Estadual }\end{array}$ & 3 & 3 & 1 \\
\hline
\end{tabular}




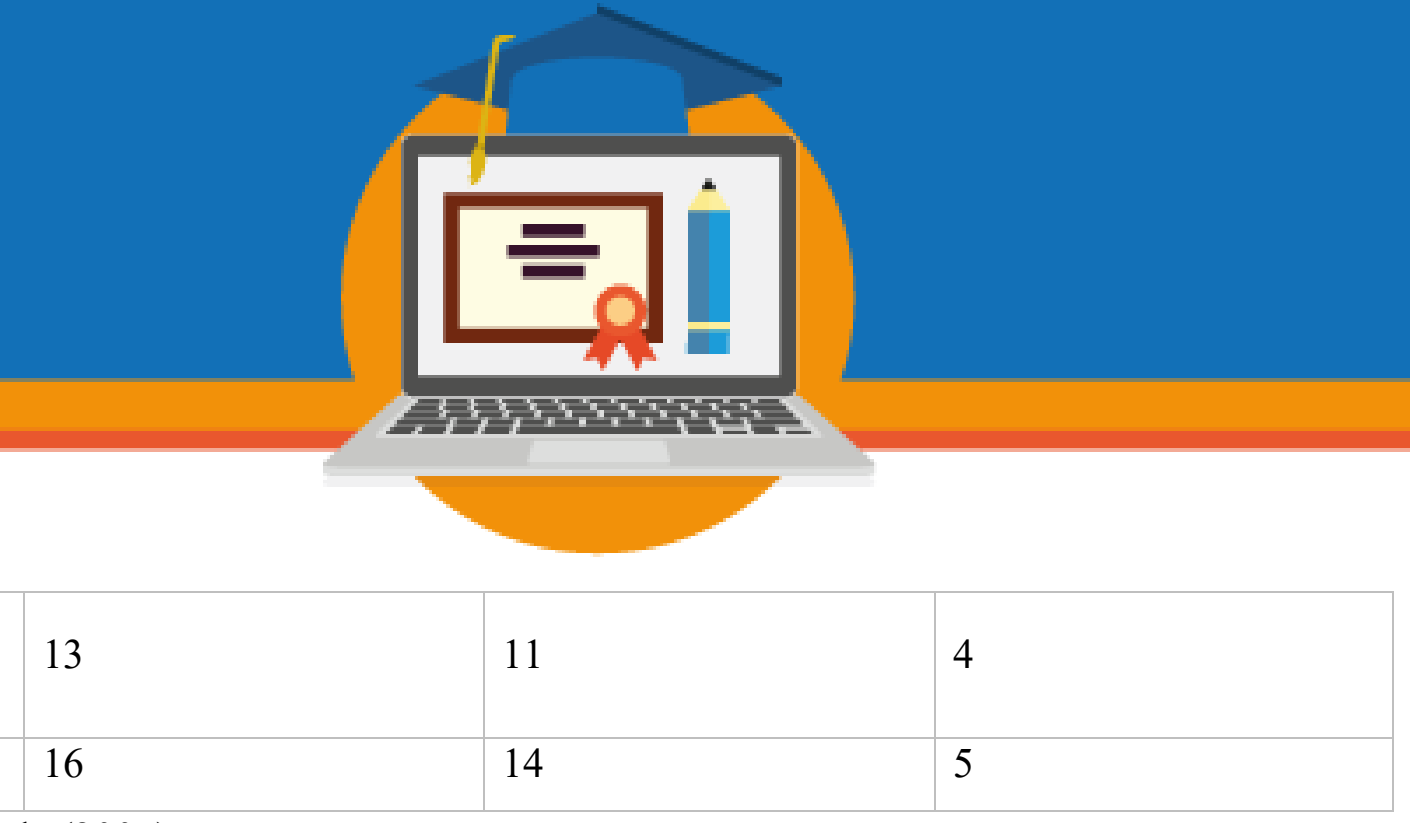

\begin{tabular}{|l|l|l|l|}
\hline $\begin{array}{l}\text { Escolas } \\
\text { Municipais }\end{array}$ & 13 & 11 & 4 \\
\hline TOTAL & 16 & 14 & 5 \\
\hline
\end{tabular}

Fonte: Cassola (2005)

Os seis encontros com o Grupo Focal foram gravados com fitas previamente adquiridas. No cenário apenas cadeiras, televisão, videocassete e a fita da Série Deficiência Mental produzida pela TV Escola.

Optamos pela gravação de forma a transcrevê-la posteriormente para melhor analisar as variáveis em observação durante a exibição do vídeo da Série Deficiência Mental produzida pela TV Escola, visando atingir nosso objetivo geral de explorar e analisar a potencialidade de utilização da TV Escola na formação contínua de professores do ensino fundamental das redes municipal e estadual que trabalham com alunos que apresentam necessidades educacionais especiais.

Objetivamos analisar a Série Deficiência Mental produção da TV Escola que tem duração média de duas horas; segundo a grade de programação que nos foi enviada pela Secretaria de Educação a Distância, a Série Deficiência Mental, foi ao ar pela primeira vez no Canal da TV Escola, no dia 26 de setembro de 1997 e atualmente ainda é exibida.

A Série Deficiência Mental produzida pela TV Escola apresenta seis programas, com o intuito de analisarmos esta Série, assistimos inúmeras vezes, a estes programas, e constatamos que o tema central desta Série é a Deficiência Mental.

Para análise do conteúdo dos vídeos, seis encontros foram necessários. Os encontros aconteceram durante duas semanas, sendo três vezes por semana, com duração de em média uma hora, dividida em torno de 30 minutos para a visualização do conteúdo do vídeo e 30 minutos para discussão como grupo.

Nos estudos com o Grupo Focal trabalhamos com os seis programas da Série Educação Especial que abordam a deficiência mental. Estes programas trazem "relatos de experiências bem-sucedidas de inclusão de crianças portadoras de deficiência mental na rede pública de ensino" e estão divididos em tópicos (TV ESCOLA, 2000, p. 62-63). 


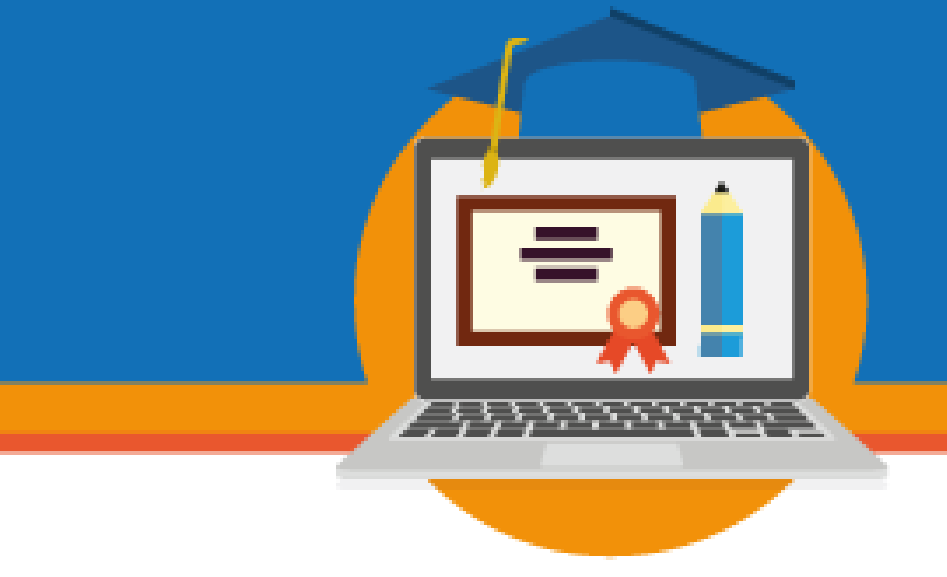

Da mesma maneira trabalhamos em tópicos com os participantes do grupo focal. Para tanto, no decorrer dos encontros avaliamos de que maneira os professores compreendem os conteúdos exibidos e ainda se o conteúdo está posto de forma que os professores possam apropriar-se dos mesmos e também se estes programas podem ser considerados como um meio de formação contínua.

Entre outros fatores priorizamos avaliar a forma e conteúdo dos programas da Série Educação Especial - Deficiência Mental; para tanto, nos pautamos em indagações, conforme guia de análise de vídeo Rosado (1996).

\section{RESULTADOS}

\subsection{OS RESULTADOS DA PESQUISA - PARTE 1}

Na primeira parte da pesquisa, os dados revelaram que $100 \%$ dos professores que trabalham com alunos que apresentam necessidades especiais nas séries iniciais do ensino fundamental, campo empírico da nossa pesquisa, não tem o hábito de utilizar os Programas produzidos pela TV Escola - Série Educação Especial em momentos de formação contínua.

Verificamos entre outras coisas, que os professores informantes - docentes de alunos que apresentam necessidades educacionais especiais nas séries iniciais do ensino fundamental, são todos graduados, possuem uma vasta experiência em sala de aula, veem formação contínua como sinônimo de cursos, sentem necessidade de formação para trabalhar com alunos que apresentam necessidades educacionais especiais, não conhecem e não utilizam os programas da Série Educação Especial produzidos pela TV Escola

Conforme os dados, os professores informantes, tem uma visão distorcida da formação contínua, pois, esta não deve ser entendida apenas como cursos isolados, e sim como uma formação centrada na própria escola. 


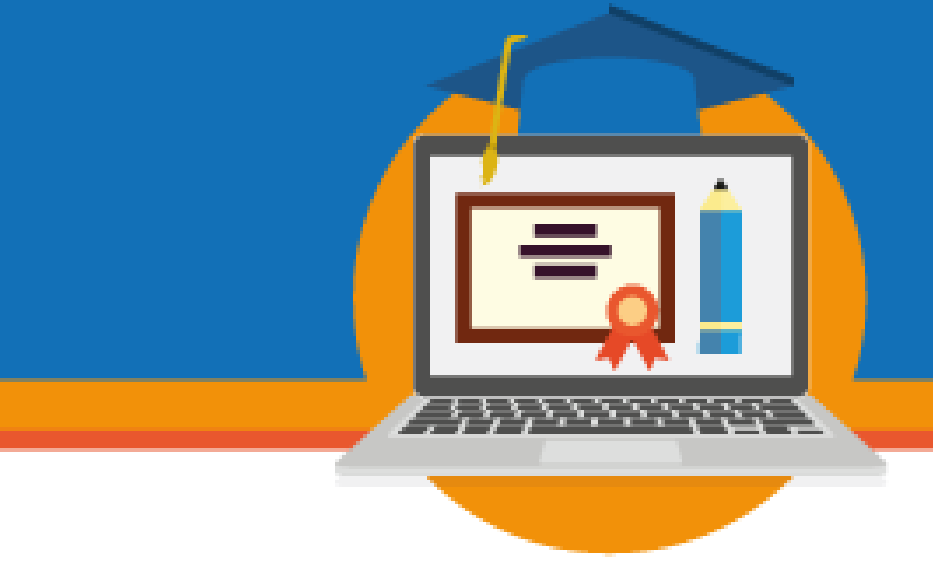

De acordo com Imbernón (2001, p. 87) “(...) a formação centrada na escola baseiase na reflexão deliberada, mediante a qual os professores elaboram suas próprias soluções em relação com os problemas práticos com que se defrontam”, ou seja, os estudos, as discussões são dirigidas a partir da própria necessidade da situação emergencial em que o problema está ancorado, possibilitando alterações significativas na práxis pedagógica.

\subsection{OS RESULTADOS DA PESQUISA - PARTE 2}

$\mathrm{Na}$ segunda parte inicial da pesquisa, através dos argumentos das entrevistas, compreendemos que os professores dos alunos que apresentam necessidades especiais sentem necessidade constante de orientação para o trabalho pedagógico a ser desenvolvido junto a eles, bem como o pouco conhecimento acerca da deficiência mental.

Entendemos de modo positivo a preocupação que os professores informantes apresentaram quanto a buscar melhor formação para trabalhar com os alunos que apresentam necessidades especiais. De certa forma percebemos que eles compreendem que a função da escola é preparar os indivíduos para o exercício da cidadania, independentemente de sua cor, raça ou religião.

A política de inclusão para todos que vivenciamos no início deste século XXI, provavelmente, irá se estender por muitos e muitos anos e o fato dos professores compreenderem que precisam se adaptar para trabalhar com esta população específica, já é um grande passo, até porque a simples inserção desta população nas escolas comuns, não significa que seus direitos enquanto cidadãos sejam respeitados.

Acreditamos que por conta de sentirem que precisam de melhor formação para trabalhar com os alunos que apresentam necessidades especiais e de não receberem capacitação no ambiente escolar, é que os professores informantes quando questionados quanto à possibilidade de adquirir conhecimento através do vídeo responderam que poderiam receber orientação através de estudos com o uso de fitas de vídeo. Este posicionamento nos possibilitou 


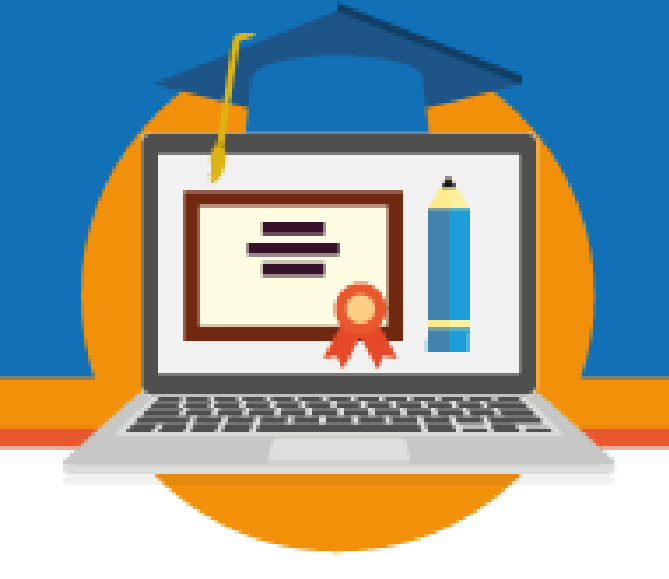

prosseguir com o segundo momento da segunda parte da nossa pesquisa, que foi a realização dos seis encontros com o Grupo Focal.

Durante os seis encontros com o Grupo Focal, registramos que os professores participantes da pesquisa, possuem/possuíam um conceito mínimo do que seja a deficiência mental, não têm conhecimento se as propostas pedagógicas das escolas que trabalham, contemplam as pessoas que apresentam necessidades educacionais especiais e sabem que a inclusão é uma realidade sem volta.

Os professores sentem necessidade de formação contínua no espaço escolar e aceitam a utilização do vídeo como auxiliar na construção do conhecimento. Após conheceram a Série Educação Especial, legitimaram os Programas da TV Escola como uma fonte rica de informações e propiciadora de reflexões da prática pedagógica no contexto escolar.

Enfim, compreendemos que os professores participantes da pesquisa desconheciam os programas da TV Escola, sentem/sentiam necessidade de capacitação, entendem/entendiam a formação contínua como cursos e após os encontros com o grupo focal, legitimam a TV Escola como uma fonte rica de informação.

Ficou explícito que os professores informantes sabem que a inclusão dos alunos que apresentam necessidades especiais é um caminho sem volta e que precisam preparar-se para trabalhar com esta população específica.

Conforme Stainback (1999, p. 25), vivenciamos grandes transformações sociais, e hoje "(...) os professores tem oportunidade de desenvolver suas habilidades profissionais em uma atmosfera de coleguismo e colaboração".

\section{CONSIDERAÇÕES FINAIS}

Conforme vimos no início deste artigo, a legislação orienta os docentes a formação contínua, no entanto, há que se fazer cumprir esse direito no espaço escolar, utilizando-se para isso, também dos meios de comunicação e informação disponíveis. 
Os programas da TV Escola têm também o intuito de proporcionar transformações e desenvolver habilidades. Cabe aos gestores escolares cumprir a legislação vigente e oferecer oportunidades de estudos aos docentes, visto que também é função da escola oferecer formação contínua aos docentes.

Para Vitkowski (2000, p. 160) a TV Escola "propõe a formação docente no ambiente escolar e desse modo, a escola deixa de ser apenas local de trabalho para se constituir também em espaço de formação".

Parece-nos que os resultados apontam que os docentes têm necessidade de formação, existem programas facilitadores/instigadores de reflexões, o que está faltando são oportunidades dentro do contexto escolar para que a formação contínua seja efetivada. A questão da oportunidade de estudos na própria escola envolve além de uma reestruturação por parte dos dirigentes, um fator político. Vitkowski (2000, p. 161) salienta que a prática de estudos no contexto educacional "implica refletir articuladamente sobre as condições socioambientais da escola e com as condições sócio profissionais do educador".

A escola enquanto instituição social tem também o dever de formar continuamente seus professores, bem como utilizar os recursos disponíveis para que a formação aconteça com sucesso. Para tanto, há necessidade de adequação e reestruturação de modo que os docentes possam ter direito aos momentos de formação contínua na própria escola e aos recursos existentes para esta formação.

Sendo assim, com esta pesquisa entendemos que a inclusão é um caminho em construção, que os alunos com necessidades especiais, precisam ter seus direitos assegurados e que cabe às escolas buscar subsídios para que isto aconteça.

Acreditamos que a formação contínua dos docentes seja um dos quesitos para a melhoria da qualidade da educação escolar oferecida para os alunos que apresentam necessidades especiais, até porque de acordo com dados da pesquisa de Oliveira e Costa (2003, p. 41) "é visível a falta de uma orientação inicial ao trabalho com alunos com necessidades educacionais especiais e este pode ser um dos pontos negativos no processo de inclusão", o que novamente justifica a necessidade de formação contínua. 
Pesquisadores apontam a escola como um espaço oportuno para esse fim. Segundo Canário (1997, p. 79), a "formação centrada na escola" tende a capacitar o professor a ser um "agente de desenvolvimento a serviço das pessoas e da organização". Este autor deixa implícito que a "formação centrada na escola", ou seja, o estudo dentro da escola, na própria prática pedagógica não deve isentar a responsabilidade da formação inicial. É imprescindível que a formação inicial seja feita de maneira bastante responsável, de forma a nos qualificar, mas a formação contínua é indispensável, até porque as competências são adquiridas no dia-a-dia dentro da escola.

Também Imbernón (2001, p. 80), entende que a "formação centrada na escola" é uma grande contribuição à formação docente, "a instituição educacional transforma-se em lugar de formação prioritária diante de outras ações formativas”. Para este autor não é somente o espaço que muda; o contexto escolar é visto como um novo enfoque para redefinir conteúdos e estratégias auxiliares a formação do professor e em contrapartida a melhoria do processo de aprendizagem, além de desenvolver um paradigma colaborativo entre os profissionais da educação.

De forma a possibilitar a reflexão crítica da própria prática pedagógica e a atender as exigências educacionais em nível de qualificações e competências, e em contrapartida a melhoria da qualidade do ensino surge à educação a distância, como um meio de propagar esta possibilidade. Assim como Hidalgo (1999) e Lima (2000), observamos que a TV Escola é um recurso que pode ser utilizado nas escolas para a formação contínua dos docentes, desde que com o auxílio de tutores ou coordenadores para auxiliar nos estudos, contudo, devemos atentar para a forma como as políticas adentram ou estão sendo implantadas nas escolas.

Esses resultados corroboram com os encontrados por Lima (2000) e Scapin (2003) em que a implantação efetiva da TV Escola exige que consideremos: 1) aspectos organizacionais da escola; 2) questões profissionais da formação docente; 3) políticas de implantação da TV Escola. E cabe aos gestores, em nível micro, diretores e supervisores das escolas e num nível macro, os responsáveis pelas políticas de formação em secretarias de educação, uma compreensão melhor desses aspectos de forma a propiciar aos docentes a 
formação contínua dentro de um contexto escolar democrático. Os integrantes deverão estar envolvidos no estabelecimento de objetivos, na solução de problemas, na tomada de decisão, no estabelecimento de padrões de desempenho e na garantia de que a escola esteja atendendo adequadamente às necessidades da sociedade como um todo e cumprindo sua função social.

Nos aspectos organizacionais da escola, há que se direcionarem recursos humanos dentro da escola, responsáveis em garantir que os professores tenham acesso a programação diária, bem como aos programas já gravados. E ainda, pessoas que possam dirigir, planejar, conceber um processo de formação contínua centrado na escola e em seus problemas.

Nas questões profissionais de formação docente há que se assegurarem momentos de estudos na proposta pedagógica da escola que possibilitem aos professores oportunidades de troca de experiências com outros profissionais da educação e ainda, formar professores para interagir com as tecnologias existentes.

No tocante as políticas de implantação da TV Escola, há que se criarem mecanismos de incorporação da TV Escola dentro das escolas e ainda, destinar recursos técnicos e financeiros para manutenção e viabilização efetiva da TV Escola.

Enfim, podemos concluir que para os professores participantes da pesquisa existe a potencialidade de utilização da TV Escola em sua formação contínua. Porém, essa potencialidade não é irrestrita e imediata, ela depende do atendimento aos aspectos organizacionais, profissionais e políticos apontados anteriormente. E, principalmente, que não seja apenas uma política de formação de professores apenas para campanhas de governo, mas que seja efetivamente implementada considerando-se todas as condições e dificuldades dessa categoria de formação.

Acreditamos que com os resultados desta pesquisa, possamos contribuir para que gestores educacionais tracem novas políticas e práticas de utilização da TV Escola nos espaços escolares. Possibilitando que a TV Escola alcance o objetivo a que veio: levar conhecimento, possibilitar reflexões e capacitar professores. Possivelmente com a relação direta entre proposta pedagógica, formação contínua e TV Escola esses objetivos sejam alcançados. 


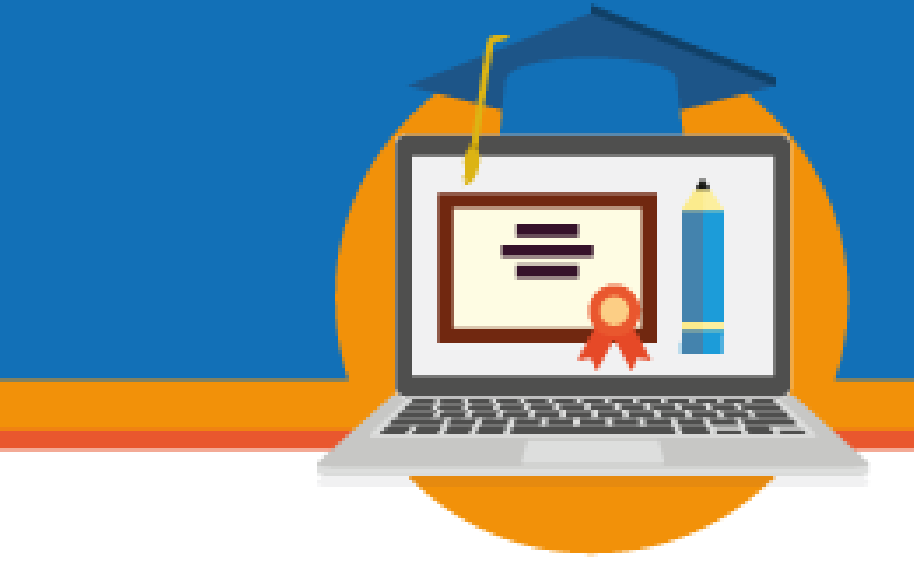

Esta é apenas uma pequena amostra de que as políticas de formação docente devem ser consoantes com a realidade e não implantadas sem que as pessoas interessadas saibam como utilizá-las. Acreditamos que outras pesquisas nesta área devam ser feitas, até para aventar novos caminhos para a reestruturação da utilização da TV Escola em contextos educacionais.

\section{REFERÊNCIAS}

BRASIL. Ministério da Educação e do Desporto. Conselho Nacional de Educação. Parecer CNE/CEB n. 17, 2001. Brasília: DOU de 17 ago 2001, seção 1, p.46.

CANÁRIO, R. A escola: lugar onde os professores aprendem. In: Anais do I Congresso Nacional de Supervisão na Formação. Portugal: Universidade de Aveiro, p. 71 a 86, 1997.

CASSOLA, R. V. Os Programas da TV Escola e a Educação Especial: possibilidades de formação de professores do ensino fundamental . Campo Grande, 2005. Dissertação (Mestrado). Universidade Católica Dom Bosco.

\section{CASTRO, A. M. D. A. Um Salto para o Futuro: uma solução na capacitação do} professor? Natal: 1998. Mestrado UFRN. Disponível em : <http: www.mec.gov.br/seed/paped/projetos.shtm>. Acesso em: 01 mar 2018.

GONDIM, S.M. G. Perfil profissional e mercado de trabalho: relação com formação acadêmica pela perspectiva de estudantes universitários. Estud. psicol. (Natal). [online]. jul.dez. 2002, vol.7, no.2 [citado 22 Maio 2005], p.299-309. Disponível na World Wide Web: <http://www.scielo.br/scielo.

HIDALGO, L. A. Supervisão Escolar e Projeto TV Escola: Um estudo na Rede Pública de Ensino Fundamental do Núcleo Regional e de Educação de Londrina/PR. Dissertação 


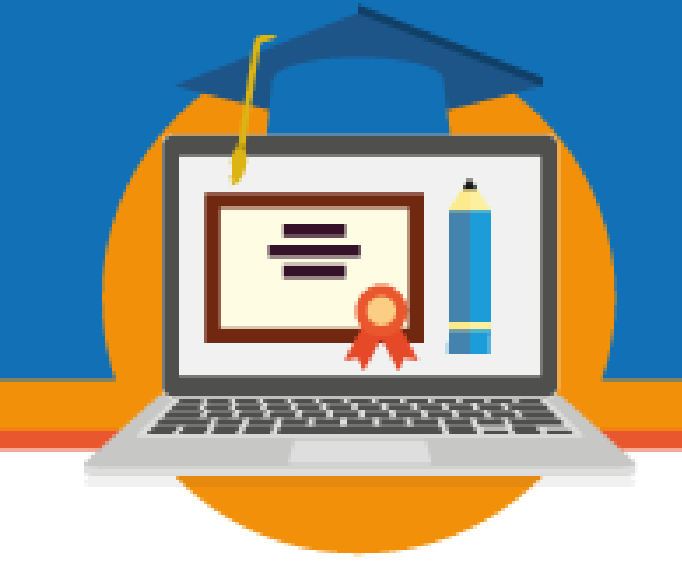

(Mestrado em Educação) Faculdade de Filosofia e Ciências, Universidade Estadual Paulista, Marília, 1999.

IMBERNON, F. Formação docente e profissional. Formar-se para a mudança e a incerteza. 2. Ed. São Paulo: Editora Cortez, 2001.

LIMA, C. M. Educação a Distância e TV Escola: apropriações de professores em formação contínua. Tese de Doutorado. Instituto de Psicologia e Fonoaudióloga. Campinas, SP: Pontifícia Universidade Católica de Campinas, 2000.

LINS, M. R. F. TV Escola e Educação a Distância: a palavra, a imagem e o professor na era da informação. PUC/RJ 1998. Disponível em: <http:// www.mec.gov.br/ seed/paped/projetos.shtm>. >. Acesso em: 01 maio 2018

LUCKESI, C. C. Democratização da educação: ensino a distância como alternativa. In: LOBO NETO,F.J.S (org.) Educação a Distância: referências e trajetórias. RJ: Associação Brasileira de Tecnologia Educacional; Brasília: Plano Editora, 2001.

MARQUES, M. B. A. Programas da SEED - TV Escola e PROINFO - impactos nas escolas públicas do RJ. EBAP/FGV-RJ. 1998. Disponível em : <http:// www.mec.gov.br/seed/paped/projetos.shtm>. >. Acesso em: 01 mar 2018.

MINAYO, M. C. S. O desafio do conhecimento: pesquisa qualitativa em saúde. $6^{\text {a }}$ edição. SP: Hucitec; Rio de Janeiro: Abrasco, 1999.

OLIVEIRA, S. S; COSTA, M. P. R. A educação inclusiva e a capacitação de professores na informática educativa no município de Fortaleza: primeiros resultados. In MARQUEZINE, M. M., ALMEIDA, M. A. e TANAKA, E. D. O. (orgs). Capacitação de professores e profissionais para Educação Especial e suas concepções sobre inclusão Londrina: Editora da Universidade Estadual de Londrina, 2003. Coleção Perspectivas Multidisciplinares em Educação Especial.

ROSADO, E. M. S. Guia de análise de vídeo. 1996. Material mimeografado, s.d. SCAPIN, I. A. S. A Formação Contínua de Professores da Ensino Médio e a TV Escola: um estudo nas escolas da rede pública de Pato Branco/PR. Dissertação (Mestrado em Educação) Faculdade de Filosofia e Ciências de Palmas, PR, 2003.

TRIVIÑOS, A. N. S. Introdução à pesquisa em Ciências Sociais. A pesquisa qualitativa em educação. São Paulo: Editora Atlas, 1997.

TV ESCOLA: Guia de Programas / Secretaria de Educação a Distância. Brasília: Ministério da Educação, SEED, 2000. 


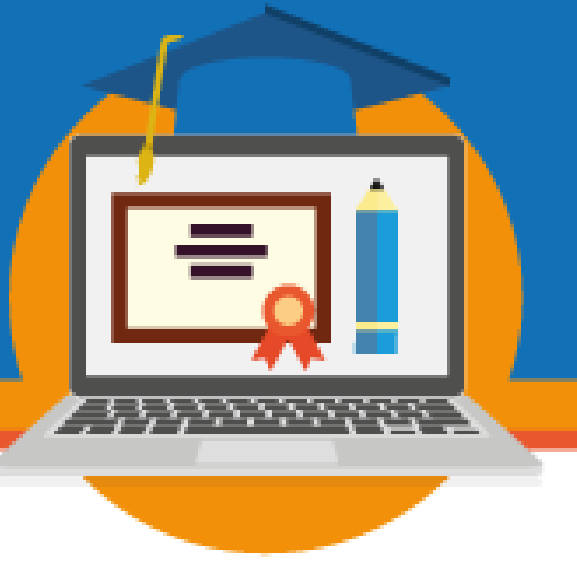

VITKOWSKI, J. R. O paradigma emergente e a integração das novas tecnologias no projeto TV Escola. In Olhar de professor, vol. 3. Ponta Grossa, nov. 2000. 